Intecoms: Journal of Information Technology and Computer Science

Volume 1 Nomor 2, Desember 2018

e-ISSN : 2614-1574

p-ISSN : 2621-3249

DOI : https://doi.org/10.31539/intecoms.v1i2.292

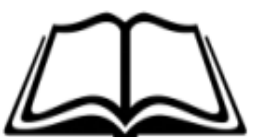

IDMEKpe

\title{
ANALISIS DAN DESAIN SISTEM INFORMASI ADMINISTRASI KEGIATAN PENELITIAN DAN PENGABDIAN MASYARAKAT MENGGUNAKAN METODE WORK SYSTEM FRAMEWORK DENGAN PEMODELAN UNIFIED MODELING LANGUAGE
}

\section{ANALYSIS AND DESIGN OF ADMINISTRATION INFORMATION SYSTEM RESEARCH ACTIVITIES AND COMMUNITY SERVICES USING WORK SYSTEM FRAMEWORK METHOD WITH MODELING UNIFIED MODELING LANGUAGE}

\author{
Afriansyah \\ Universitas Lancang Kuning \\ afriansyah@unilak.ac.id
}

\begin{abstract}
University can't be separated from the Tri Dharma namely in the fields of education, research and community service. Institute for Research and Community Services Lancang Kuning University has launched a strategic framework for research through the Research Master Plan (RIP) and the Roadmap Research to support research results and superior quality. One of them by building an Information Systems Research Activities Administration and Community Services seeks to streamline the work of the staff LPPM and also makes it easy for researchers in particular lecturers and reviewers in their duties. In this system, the researchers register their proposals online. Furthermore, staff LPPM recaps the number of proposals on all types of grants that is then distributed to the reviewer to assess. Administration Information System Research Activities and Community Service is used method of analysis Work System Framework. Methods of work system framework, expected later able to provide a description of the process or activity system that uses information technology or other resources. Modeling design methodology using Unified Modeling Language (UML) and MySql database.
\end{abstract}

Keywords : Information Systems, Administration, Work System Framework, UML

\begin{abstract}
ABSTRAK
Perguruan Tinggi tidak lepas dari Tri Dharma yaitu dalam bidang pendidikan, penelitian dan pengabdian kepada masyarakat. Lembaga Penelitian dan Pengabdian Kepada Masyarakat Universitas Lancang Kuning telah mencanangkan kerangka strategis penelitian melalui Rencana Induk Penelitian (RIP) dan Roadmap Penelitian untuk mendukung hasil riset yang unggul dan berkualitas. Salah satunya dengan membangun suatu Sistem Informasi Administrasi Kegiatan Penelitian dan Pengabdian Masyarakat yang diupayakan untuk mengefektifkan kerja dari staf LPPM dan juga memberikan kemudahan bagi peneliti khususnya dosen dan reviewer dalam melaksanakan tugasnya. Pada sistem ini, para peneliti meregistrasikan proposalnya secara online. Selanjutnya, staff LPPM melakukan rekap terhadap jumlah proposal pada semua jenis hibah yang ada kemudian mendistribusikannya kepada reviewer untuk dinilai. Sistem Informasi Administrasi Kegiatan Penelitian dan Pengabdian Masyarakat ini digunakan metode analisis Work System Framework. Metode work system framework, diharapkan nantinya mampu memberikan gambaran proses atau kegiatan system yang menggunakan teknologi informasi atau pun sumber daya lainnya. Metode perancangan menggunakan pemodelan Unified Modeling Language (UML) serta database MySql.
\end{abstract}

Kata Kunci: Sistem Informasi, Administrasi, Work System Framework, UML

\section{PENDAHULUAN}

Perguruan Tinggi tidak lepas dari Tri Dharmayaitu dalam bidang pendidikan, penelitiandan pengabdian kepada masyarakat. Lembaga

Penelitian dan Pengabdian Kepada Masyarakat Universitas Lancang Kuning telah mencanangkan kerangka 
strategis penelitian melalui Rencana Induk Penelitian (RIP) dan Roadmap Penelitian untuk mendukung hasil riset yang unggul dan berkualitas. Salah satunya dengan membangun suatu Sistem Informasi Administrasi Kegiatan Penelitian dan Pengabdian Masyarakat yang diupayakan untuk mengefektifkan kerja dari staf LPPM dan juga memberikan kemudahan bagi peneliti khususnya dosen dan reviewer dalam melaksanakan tugasnya(Dikti, 2016). Pada sistem ini, para peneliti meregistrasikan proposalnya secara online. Selanjutnya, staff LPPM melakukan rekap terhadap jumlah proposal pada semua jenis hibah yang ada kemudian mendistribusikannya kepada reviewer untuk dinilai. Sistem Informasi Administrasi Kegiatan Penelitian dan Pengabdian Masyarakat ini digunakan metode analisis Work System Framework.

Metode work system framework, diharapkan nantinya mampu memberikan gambaran proses atau kegiatan system yang menggunakan teknologi informasi atau pun sumber daya lainnya. Metode perancangan menggunakan pemodelan Unified Modeling Language (UML) serta database MySql. Pada penelitian sebelumnya Williandy dkk (2016) merancang sistem penelitian dan pengabdian pada masyarakat Fakultas Teknik Universitas Lampung menggunakan PHP dan MySQL begitu juga dengan Hamzah (2016) di Unversitas Respati.

Work System Framework (Sistem Kerja Framework) adalah suatu penggambaran konseptual dari sebuah sistem kerja yang sedang berjalan pada suatu perusahaan atau organisasi, dimana peserta dan/atau mesin manusia melakukan pekerjaan (proses dan kegiatan) menggunakan informasi, teknologi, dan sumber daya lainnya untuk menghasilkan produk / jasa bagi pelanggan internal atau eksternal (Alter S., 2013).

\section{METODE PENELITIAN}

Work System Framework memberikan gambaran sistem yang sedang dipelajari, mengidentifikasi masalah dan peluang, menggambarkan perubahan yang mungkin terjadi dan melacak bagaimana perubahan tersebut mungkin mempengaruhi bagian lain dari sistem kerja.

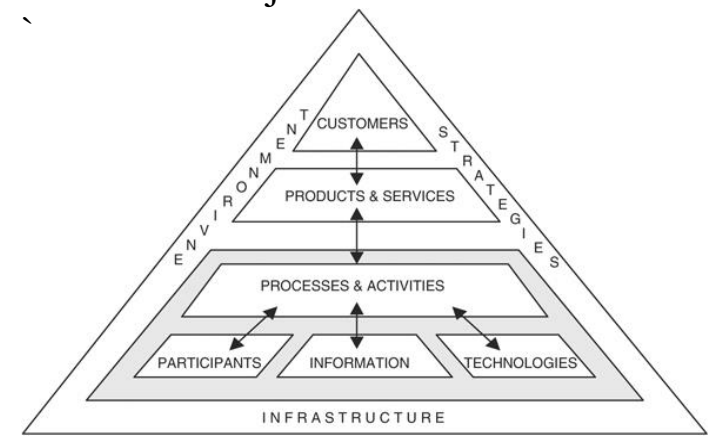

Gambar. 1 Work System Framework

\section{Komponen-komponen pada Work System Framework}

Komponen-komponen yang ada pada Work System Framework adalah sebagai berikut (Rohman, 2009):

\section{Customer}

Customer adalah orang/ organisasi yang menerima secara langsung produk atau service yang dihasilkan oleh sistem, baik konsumen dari luar organisasi atau dan dalam organisasi. Customer terbagi menjadi pelanggan eksternal masyarakat) yang menerima barang dan jasa serta pelanggan internal (dari dalam organisasi sendiri).

\section{Product and Services}

Product and Services merupakan gabungan dari benda berwujud fisik, informasi dan layanan yang dihasilkan oleh work system untuk para pelanggan. Tujuan terciptanya work system guna menghasilkan barang dan jasa. 


\section{Business Process}

Business Process merupakan kumpulan urutan-urutan kerja atau aktivitas yang dijalankan di dalam work system.

\section{Participants}

Peserta (participants) adalah orang yang melakukan beberapa pekerjaan pada proses bisnis disebut sebagai peserta bagi work system.

\section{Information}

Informasi (Information) adalah yang digunakan oleh participants untuk mengerjakan pekerjaannya..

\section{Technology}

Teknologi (Technology) terdiri dari perangkat keras, perangkat lunak, dan perkakas-perkakas lainnya yang digunakan oleh peserta ketika melakukan pekerjaannya.

\section{Context atau Environtment}

Merupakan bagian-bagian seperti organisasi, persaingan, teknis, dan peraturan yang terdapat pada work system yang sedang beroperasi.

\section{Infrastructure}

Infrastruktur (infrastructure) meliputi segala sumber daya, baik manusia, informasi, dan teknis yang digunakan oleh work system walaupun sumbersumber daya ada dan dikelola di luar work system dan juga digunakan oleh work system lainnya.

\section{Strategy}

Hubungan antara komponen ini dengan strategi organisasi boleh saja tidak menjadi perhatian, namun terkadang dengan melihat strategi organisasi akan membantu dalam menjelaskan mengapa work system sepeti saat ini.
Unified ModelingLanguage (UML)

UML berfungsi sebagai jembatan dalam mengkomunikasikan beberapa aspek dalam sistem melalui sejumlah elemen grafis yang bisa diakomodasikan menjadi diagram. UML mempunyai banyak diagram yang dapat mengakomodasikan berbagai sudut pandang dari perangkat lunak yang terdiri dijelaskan pada sub-sub bab berikut ini.

\section{HASIL DAN PEMBAHASAN}

\section{Analisa Sistem yang Diusulkan}

Analisa sistem merupakan salah satu tahap dalam siklus hidup pengembangan sistem informasi yang merupakan tahap bagi analis sistem melakukan desain atau perancangan terhadap sistem baru yang akan dibuat. Adapun metode yang digunakan dalam analisis sistem ini yaitu Work System Framework (WSF).

Gambar. 2 Cause Effect (Sebab Akibat) Sistem Usulan 
Gambar di atas merupakan gambaran hubungan sebab akibat (Cause Effect) yang timbul dari perubahan sistem lama yang konvensional ke sistem usulan (baru) yang berbasis teknologi informasi.

\section{Work System Framework (WSF) yang Diusulkan}

Berikut ini adalah tabel analisa usulan sistem informasi administrasi kegiatan penelitian dan pengabdian masyarakat di LPPM Universitas Lancang Kuning Pekanbaru dengan metode work system framework.

Tabel. 1 Analisa Usulan Sistem Informasi Administrasi Kegiatan Penelitian dan Pengabdian Masyarakat dengan Metode Work System Framework

\begin{tabular}{ll}
\hline - Staff LPPM & - Informasi tawaran PPM \\
-Admin & - Proposal usulan PPM \\
- Dosen/ Peneliti & - Laporan progres PPM \\
- Reviewer & - Informasi jadwal \\
& seminar PPM
\end{tabular}

\section{Work Practices (Major Activities or Processes)}

1. ntri akses masuk / Login oleh User sistem

2. Upload data User (admin,dosen, peneliti, reviewer)

3. Entri informasi tawaran penelitian dan pengabdian

4. Entri data usulan penelitian dan pengabdian

5. Entri nilai dan ranking proposal penelitian

6. Entri jadwal monitoring evaluasi

7. Entri jadwal seminar hasil penelitian

8. Entri pengumuman seminar hasil penelitian dan pengabdian

9. Entri data rekapitulasi penelitian dan pengabdian

10. Cetak laporan kegiatan penelitian dan pengabdian

\begin{tabular}{lll}
\hline Participants & Information & Technologies \\
\hline - Admin & - Informasi & - Computer \\
- Staff LPPM tawaran & - Internet \\
- Dosen/ & penelitian & Network \\
Peneliti & - Proposal usulan & - Database \\
- Reviewer & PPM & - Server \\
\hline
\end{tabular}

Berdasarkan penjabaran analisa usulan sistem informasi administrasi kegiatan penelitian dan pengabdian masyarakat di LPPM Universitas Lancang Kuning Pekanbaru dengan metode work system framework pada tabel di atas, maka penulis menyajikan Work System Framework pada sistem baru yaitu:

Tabel. 2 Work System Framework Sistem Informasi Administrasi Kegiatan Penelitian dan Pengabdian Masyarakat LPPM Universitas Lancang Kuning

\begin{tabular}{|c|c|c|}
\hline No & Komponen & Elemen \\
\hline 1. & Customers & $\begin{array}{l}\text { 1. Staff LPPM adalah } \\
\text { karyawan unit LPPM } \\
\text { Universitas Lancang } \\
\text { Kuning yang } \\
\text { mengelola kegiatan } \\
\text { penelitian dan } \\
\text { pengabdian kepada } \\
\text { masyarakat yang } \\
\text { dilakukan oleh } \\
\text { dosen. } \\
\text { 2. Admin adalah } \\
\text { karyawan unit LPPM } \\
\text { Universitas Lancang } \\
\text { Kuning yang } \\
\text { ditugaskan khusus } \\
\text { untuk bertanggung } \\
\text { jawab dalam } \\
\text { mengelola sistem } \\
\text { informasi kegiatan } \\
\text { PPM yang dilakukan } \\
\text { oleh dosen. } \\
\text { Dosen Peneliti } \\
\text { adalah dosen yang } \\
\text { melakukan kegiatan } \\
\text { PPM } \\
\text { Reviewer adalah } \\
\text { dosen yang } \\
\text { memenuhi } \\
\text { persyaratan yang } \\
\text { telah ditentukan dan } \\
\text { ditetapkan oleh } \\
\text { LPPM dengan tugas } \\
\text { untuk melakukan } \\
\text { review terhadap } \\
\text { proposal yang } \\
\text { diajukan. }\end{array}$ \\
\hline 2. & $\begin{array}{l}\text { Product \& } \\
\text { Services }\end{array}$ & $\begin{array}{l}\text { 1. Informasi tawaran } \\
\text { PPM adalah informasi } \\
\text { peluang dari sponsor } \\
\text { atau penyandang dana } \\
\text { penelitian dan } \\
\text { pengabdian }\end{array}$ \\
\hline
\end{tabular}




\begin{tabular}{|c|c|}
\hline & $\begin{array}{l}\text { masyarakat. } \\
\text { 2. Proposal usulan } \\
\text { kegiatan PPM adalah } \\
\text { dokumen usulan } \\
\text { penelitian dan } \\
\text { pengabdian } \\
\text { masyarakat yang akan } \\
\text { dilakukan oleh dosen } \\
\text { peneliti. } \\
\text { 3. Laporan Progres } \\
\text { kegiatan PPM adalah } \\
\text { dokumen pelaporan } \\
\text { kegiatan PPM yang } \\
\text { sedang dilaksanakan } \\
\text { dengan progres 70\%. } \\
\text { 4. Informasi jadwal } \\
\text { seminar PPM adalah } \\
\text { jadwal yang disusun } \\
\text { oleh staff LPPM untuk } \\
\text { pelaksanaan seminar } \\
\text { proposal, monev dan } \\
\text { seminar hasil yang } \\
\text { akan dilakukan oleh } \\
\text { dosen peneliti. }\end{array}$ \\
\hline $\begin{array}{l}\text { 3. } \begin{array}{l}\text { Process and } \\
\text { Activities }\end{array}\end{array}$ & $\begin{array}{l}\text { 1. Menambah Data } \\
\text { User dilakukan oleh } \\
\text { Admin pada sistem } \\
\text { sesuai dengan } \\
\text { permintaan pengguna } \\
\text { sistem yaitu staff } \\
\text { LPPM, dosen } \\
\text { peneliti dan } \\
\text { Reviewer. } \\
\text { 2. Entri Berita dan } \\
\text { Pengumuman } \\
\text { dilakukan oleh } \\
\text { Admin. Berita dan } \\
\text { pengumuman dapat } \\
\text { dilihat oleh } U s e r \\
\text { pada sistem. } \\
\text { 3. Entri dokumen } \\
\text { proposal kegiatan } \\
\text { PPM dilakukan oleh } \\
\text { Dosen Peneliti. } \\
\text { 4. Pengambilan dan } \\
\text { Penyediaan } \\
\text { Dokumen PPM } \\
\text { terdiri dari jadwal } \\
\text { seminar, menginput } \\
\text { dokumen proposal } \\
\text { PPM. } \\
\text { 5. Proses cetak laporan } \\
\text { kegiatan penelitian } \\
\text { dan pengabdian } \\
\text { masyarakat. }\end{array}$ \\
\hline
\end{tabular}

\begin{tabular}{ll}
\hline Participants $\quad$ Staff LPPM \\
bertanggung jawab \\
terhadap proses dan \\
seleksi proposal \\
yang masuk dari \\
seluruh Dosen \\
Peneliti. \\
2. \\
Admin bertanggung \\
jawab terhadap \\
proses dan seleksi \\
proposal yang \\
masuk dari seluruh \\
Dosen Peneliti. \\
Dosen Peneliti \\
wajib mematuhi \\
aturan yang berlaku \\
Reviewer wajib \\
melaksanakan tugas \\
\\
dan fungsinya \\
sebagaimana \\
mestinya. \\
6.
\end{tabular}




\begin{tabular}{|c|c|}
\hline & kegiatan PPM. \\
\hline Technology & 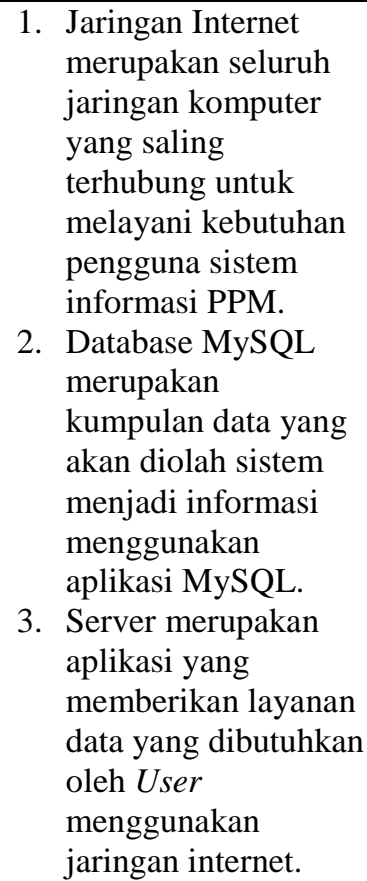 \\
\hline 7. Infrastructure & $\begin{array}{l}\text { 1. } \begin{array}{l}\text { Sistem Informasi } \\
\text { adalah sistem } \\
\text { informasi }\end{array} \\
\text { administrasi } \\
\text { kegiatan penelitian } \\
\text { dan pengabdian } \\
\text { masyarakat LPPM } \\
\text { Unilak. } \\
\text { 2. } \\
\text { Struktur organisasi } \\
\text { adalah hubungan } \\
\text { tiap bagian LPPM } \\
\text { yang bekerja sama } \\
\text { untuk menjalankan } \\
\text { kegiatan operasional } \\
\text { PPM. }\end{array}$ \\
\hline
\end{tabular}

8. Environtment 1. Pemberian Penghargaan merupakan reward atas laporan hasil kegiatan PPM berdasarkan nilai tertinggi yang diberikan Reviewer, yaitu dengan memasang pengumuman pada sistem dan memasang spanduk pada tempat umum yang telah disediakan.

2. Kontrak PPM merupakan bukti

\begin{tabular}{|c|c|c|}
\hline & & $\begin{array}{l}\text { perjanjian dosen } \\
\text { peneliti dan } \\
\text { pelaksana kegiatan } \\
\text { pengabdian yang } \\
\text { didokumentasikan } \\
\text { disertai lembar } \\
\text { perjanjian dan foto } \\
\text { kegiatan. }\end{array}$ \\
\hline 9. $\quad$ Strategy & 2. & $\begin{array}{l}\text { Standar Operasional } \\
\text { Prosedur (SOP) } \\
\text { ditetapkan untuk } \\
\text { menjamin proses } \\
\text { kegiatan PPM dapat } \\
\text { berjalan secara } \\
\text { teratur, efektif dan } \\
\text { efisien sesuai dengan } \\
\text { aturan yang berlaku. } \\
\text { Panduan } \\
\text { Pelaksanaan } \\
\text { Penelitian dan } \\
\text { Pengabdian } \\
\text { Masyarakat } \\
\text { merupakan } \\
\text { kebijakan } \\
\text { pengelolaan yang } \\
\text { diterbitkan oleh } \\
\text { LPPM berdasarkan } \\
\text { standar pedoman } \\
\text { penelitian dan } \\
\text { pengabdian } \\
\text { masyarakat yang } \\
\text { dikeluarkan oleh } \\
\text { Ristek Dikti. }\end{array}$ \\
\hline
\end{tabular}

Berdasarkan analisis sistem usulan yang telah diuraikan, maka proses bisnis yang ada pada sistem informasi administrasi kegiatan penelitian dan pengabdian LPPM Universitas Lancang Kuning dibagi menjadi lima proses yaitu:

1. Proses Menambah Data User Kegiatan Upload Data User dilakukan oleh Admin sistem informasi administrasi kegiatan penelitian dan pengabdian LPPM Universitas Lancang Kuning. Setiap pengguna sistem informasi PPM baru melakukan permintaan hak ases ke dalam sistem dengan melaporkan permintaan Username dan Password. Selanjutnya Admin menginputkan 
user baru pada menu upload data user. Setelah dilakukan penambahan user, Admin memberikan username dan password sesuai dengan permintaan. Adapun yang menjadi user dan proses bisnis pada sistem informasi administrasi kegiatan penelitian dan pengabdian LPPM Universitas Lancang Kuning Pekanbaru sebagai berikut:

a. Staff LPPM

Proses mendaftarkan Staff LPPM agar mempunyai akses ke dalam sistem informasi administrasi kegiatan PPM yang akan dibangun.

b. Reviewer

Proses mendaftarkan dosen yang menjadi reviewer agar sistem informasi administrasi kegiatan PPM yang akan dibangun, sehingga dapat melakukan pemeriksaan, monitoring dan penilaian terhadap usulan penelitian dan pengabdian yang masuk di dalam sistem.

c. Dosen Peneliti

$\begin{array}{lcr}\text { Proses } & \text { mendaftarkan } & \text { dosen } \\ \text { sebagai } & \text { pengguna } & \text { sistem } \\ \text { informasi. } & \text { Kegiatan } & \text { yang } \\ \text { dilakukan oleh dosen/peneliti } & \text { praitu meregistrasikan proposal } \\ \text { yaitu } & \text { pulan kegiatan PPM. }\end{array}$

2. Proses Entri Dokumen Proposal Kegiatan PPM

Proses memasukkan dokumen proposal kegiatan penelitian dan pengabdian masyarakat dilakukan oleh dosen peneliti. Proposal usulan yang akan diajukan terlebih dahulu dimasukkan ke dalam sistem agar staff LPPM dapat merekapitulasi proposal usulan kegiatan PPM. Berdasarkan rekapitulasi tersebut, staff LPPM dapat membuat jadwal pelaksanaan sidang seminar proposal usulan kegiatan PPM.
3. Proses Entri Berita dan Pengumuman

Proses entri berita dan pengumuman adalah proses untuk penginputan informasi berita terbaru seperti tawaran penelitian dan pengumuman kegiatan PPM, Adapun jenis pengumuman yang dimasukkan ke dalam sistem yaitu :

a. Pengumuman Jadwal Seminar Proposal Kegiatan PPM

Jadwal seminar proposal kegiatan PPM adalah informasi seminar proposal kegiatan PPM yang telah disusun oleh staff LPPM. Jadwal seminar terdiri dari, seminar proposal, monitoring dan evaluasi dan seminar hasil.

b. Informasi Tawaran Penelitian Dan Pengabdian

Tawaran penelitian merupakan informasi mengenai peluangpeluang penelitian dan pengabdian, baik yang disponsori oleh Universitas, Fakultas, maupun DIKTI. Informasi tawaran penelitian dan pengabdian ini diperbaharui oleh staff LPPM di dalam sistem.

c. Program Penelitian dan Pengabdian

Program penelitian dan pengabdian adalah jenis atau skim penelitian dan pengabdian masyarakat yang akan dilakukan oleh dosen/peneliti. Terdiri dari beberapa program penelitian dan pengabdian masyarakat yang diberlakukan yaitu:
1) Penelitian Peningkatan Kapasitas Dosen Muda
2) Penelitian Utama
3) Penelitian Guru Besar
4) Pengabdian Ipteks bagi Masyarakat (IbM)

4. Proses Penyediaan dan Pengambilan Dokumen Kegiatan PPM
Proses
penyediaan
dan

pengambilan dokumen yaitu 
dokumen -dokumen yang diperlukan oleh user disediakan pada sistem, misalnya form pendaftaran penelitian, jadwal seminar usulan, pengumuman hasil penelitian. Pada proses pengambilan dokumen user dapat melakukan perintah upload dan download pada menu yang tersedia pada sistem usulan.

5. Proses Cetak Laporan Kegiatan Penelitian Dan Pengabdian Masyarakat

Proses cetak laporan kegiatan penelitian dan pengabdian masyarakat adalah proses-proses yang dilakukan terkait dengan LPPM Universitas Lancang Kuning Pekanbaru. Laporan-laporan yang dibutuhkan oleh Ketua LPPM dapat dicetak langsung dari sistem oleh admin. Beberapa laporan yang tersedia antara lain: penelitian dan pengabdian masyarakat
a. Laporan rekapitulasi proposal
b. Laporan monitoring dan evaluasi penelitian dan pengabdian masyarakat
c. Laporan kegiatan penelitian dan dan pengabdian masyarakat

\section{Desain Sistem}

Desain sistem pada penelitian ini menggunakan pemodelan Unified Modeling Language. Unified Modelling Language (UML) digunakan untuk penggambaran sistem secara garis besar dan desain sistem secara detail untuk membantu dalam pembuatan sistem. Adapun UML yang digunakan pada sistem ini yaitu use case diagram, skenario diagram, activity diagram, sequence diagram dan class diagram.

\section{a. Use Case Diagram}

Pemodelan Use Case berfungsi untuk mengambarkan kebutuhan fungsional dan menggambarkan kelakuan (behavior) sistem yang akan dibuat serta mendeskripsikan sebuah interaksi antara satu atau lebih aktor dengan sistem yang akan dibangun.

Berdasarkan aktor dan identifikasi Use Case yang telah ditentukan pada tabel-tabel di atas, maka dapat dimodelkan dalam bentuk Use Case diagram seperti pada gambar di bawah ini:

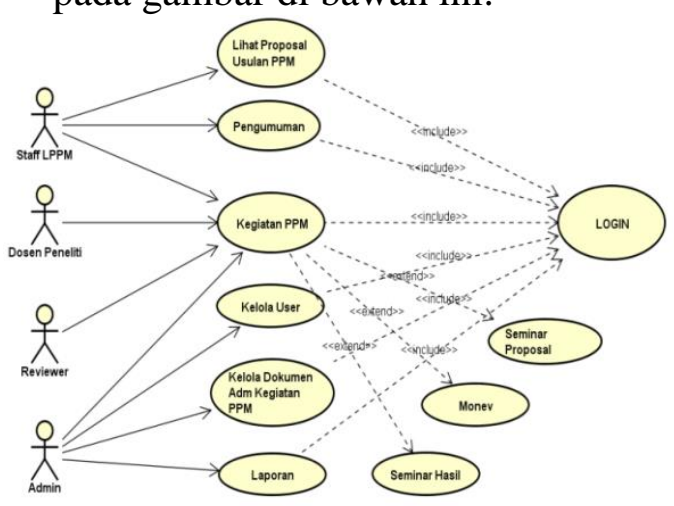

Gambar 3 Use Case Diagram

\section{b. Skenario Diagram}

Guna memperjelas fiturfitur yang akan ditampilkan pada sisteminformasi administrasi kegiatan penelitian dan pengabdian LPPM Universitas Lancang Kuning maka dibutuhkan Skenario Diagram yang berguna untuk menjelaskan sistem secara detail seperti di bawah ini:

\section{1) Skenario Diagram Login}

Tabel. 3 Skenario Diagram Use Case Login

\begin{tabular}{lll}
\hline 1 & & Use Case Login \\
\hline & Nama & Login \\
& Aktor & Staff LPPM, Dosen \\
& Peneliti,Reviewer dan \\
& Admin \\
& Tujuan & Menentukan hak akses \\
& masing-masing aktor \\
& Kondisi & Tampilan Login sistem \\
& Awal & informasi administrasi PPM \\
Kondisi & Menampilkan menu sesuai \\
\hline
\end{tabular}




\begin{tabular}{lll}
\hline & Akhir & hak akses aktor \\
\hline 2 & Skenario Utama (Basic Flow) \\
\hline Aktor & Sistem \\
Memilih & Menampilan halaman depan \\
menu login & Menampillkan form login \\
Mengisi & Meng-autentifikasi form \\
username, & login \\
level dan & Menampilkan halaman \\
password & sesuai hak akses dari \\
Aktor & masing-masing aktor \\
menekan & \\
tombol & \\
login & \\
& \\
\hline Skenario Alternatif (Alternative Flow) : \\
Jika Autentifikasi User gagal \\
\hline Aktor & Sistem \\
& Menampilkan pesan error : \\
Aktor & "Username / Password \\
mengisi & tidak valid" \\
form Login & Meng-autentifikasi \\
& formLogin \\
& Menampilkan halaman \\
& depan \\
\hline
\end{tabular}

\section{2) Skenario Diagram Lihat Proposal Usulan PPM}

Tabel. 4 Skenario Diagram Use Case Skenario Diagram Lihat Proposal Usulan PPM

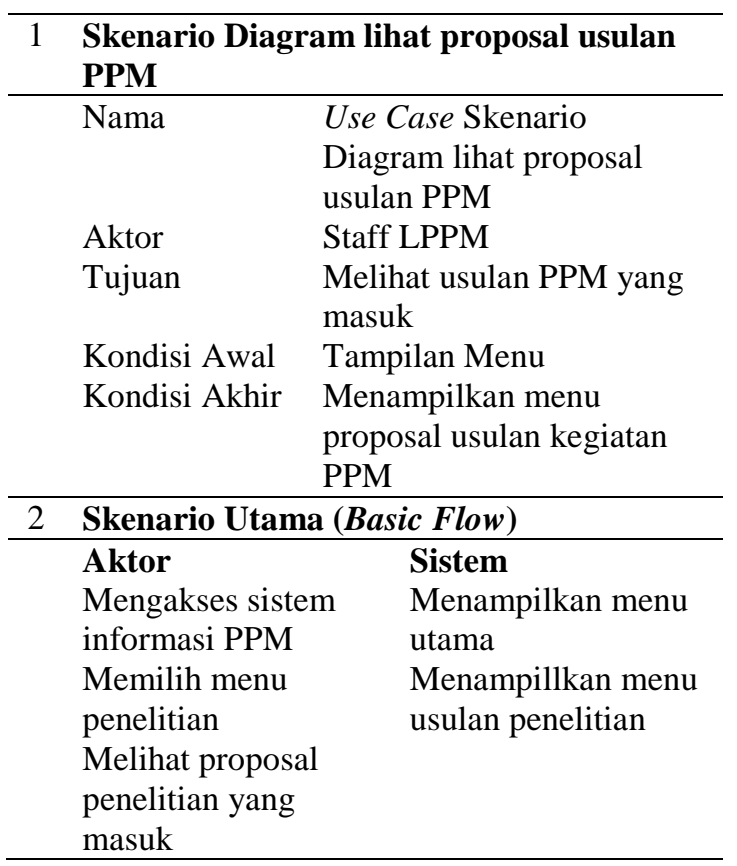

\section{3) Skenario Pengumuman}

Diagram

Tabel. 5 Skenario Diagram Use Case Skenario Diagram Pengumuman

\begin{tabular}{lll}
\hline 1 & Skenario Diagram Pengumuman \\
\hline Nama & $\begin{array}{l}\text { Use Case Skenario } \\
\text { Diagram pengumuman }\end{array}$ \\
Aktor & $\begin{array}{l}\text { Staff LPPM } \\
\text { Tujuan }\end{array}$ & $\begin{array}{l}\text { Memperbaharui } \\
\text { pengumuman kegiatan }\end{array}$ \\
& PPM \\
Kondisi Awal & Tampilan Menu \\
Kondisi Akhir & Menampilkan menu \\
& pengumuman \\
\hline Skenario Utama (Basic Flow)
\end{tabular}

\section{4) Skenario Diagram Kegiatan PPM}

Tabel. 6 Skenario Diagram Use Case Skenario Diagram Kegiatan PPM

\begin{tabular}{|c|c|c|c|}
\hline \multirow[t]{6}{*}{1} & \multicolumn{3}{|c|}{ Skenario Diagram Kegiatan PPM } \\
\hline & Nama & \multicolumn{2}{|c|}{$\begin{array}{l}\text { Use Case Skenario Kegiatan } \\
\text { PPM }\end{array}$} \\
\hline & Aktor & \multicolumn{2}{|c|}{$\begin{array}{l}\text { Staff LPPM, Admin, Dosen } \\
\text { Peneliti, Reviewer }\end{array}$} \\
\hline & Tujuan & \multicolumn{2}{|c|}{ Mengolah data kegiatan } \\
\hline & Kondisi Awal & \multicolumn{2}{|c|}{ Tampilan Menu } \\
\hline & Kondisi Akhir & \multicolumn{2}{|c|}{ Menampilkan menu kegiatan } \\
\hline \multirow[t]{7}{*}{2} & \multicolumn{3}{|c|}{ Skenario Utama (Basic Flow) } \\
\hline & \multicolumn{2}{|c|}{ Aktor } & Sistem \\
\hline & \multicolumn{2}{|c|}{$\begin{array}{l}\text { 1. Mengakses sistem } \\
\text { informasi PPM }\end{array}$} & $\begin{array}{l}\text { 2. Menampilkan } \\
\text { halaman utama }\end{array}$ \\
\hline & \multicolumn{2}{|c|}{ 3. Memilih menu } & 4. Menampillkan \\
\hline & \multicolumn{2}{|c|}{ kegiatan PPM } & menu kegiatan \\
\hline & \multicolumn{2}{|c|}{ 5. Mengolah data } & $\mathrm{PPM}$ \\
\hline & \multicolumn{2}{|c|}{ kegiatan PPM } & \\
\hline
\end{tabular}




\section{Activity Diagram Dosen Peneliti}

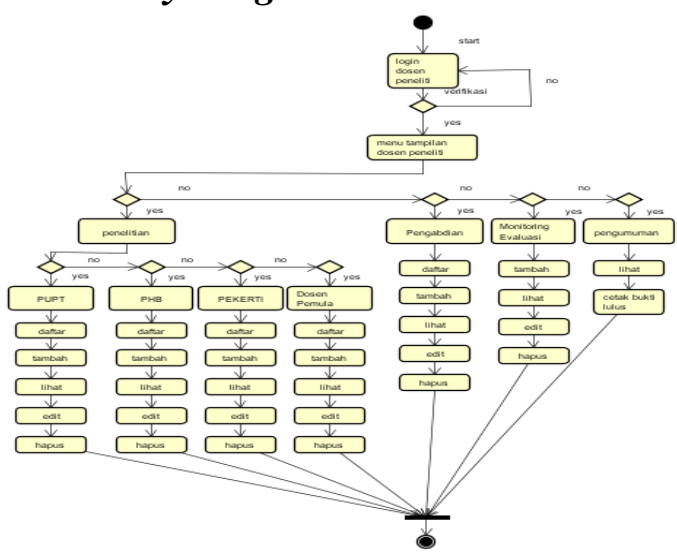

Gambar. 6 Activity Diagram Dosen Peneliti

\section{Activity Diagram Reviewer}

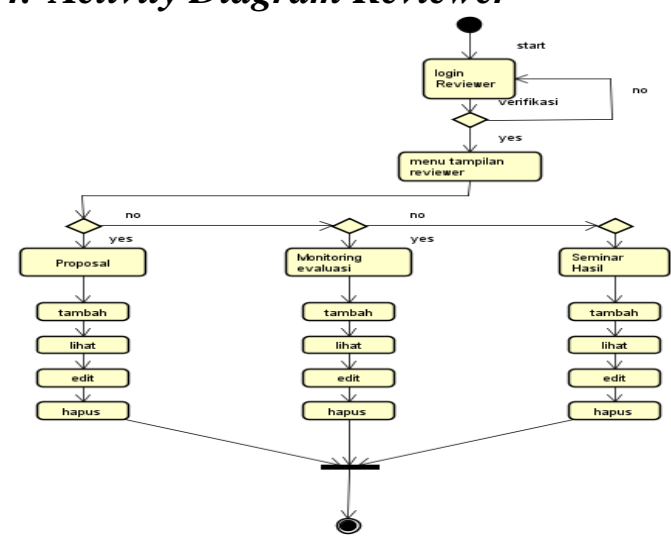

Gambar. 7 Activity Diagram Reviewer

\section{Sequence Diagram}

1. Sequence Diagram Lihat Proposal Usulan Penelitian

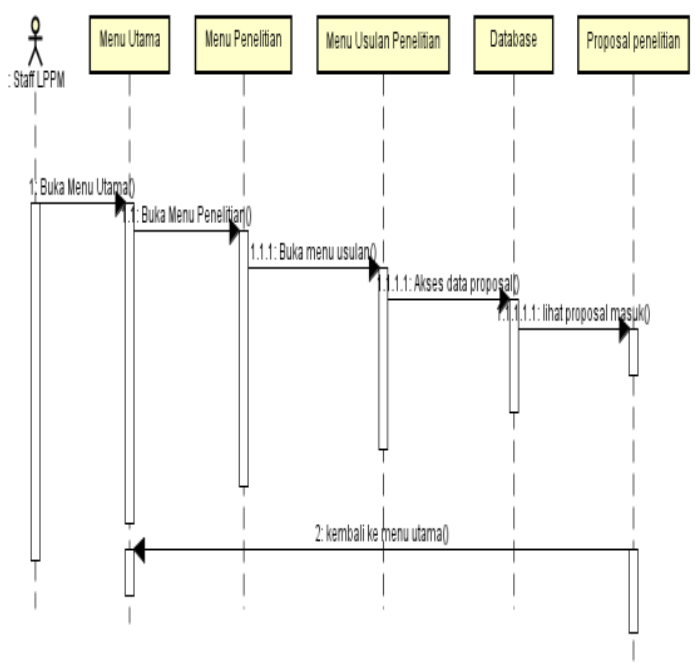

Gambar. 8 Sequence Diagram Lihat Proposal Usulan Penelitian

\section{Sequence Diagram Pengumuman}

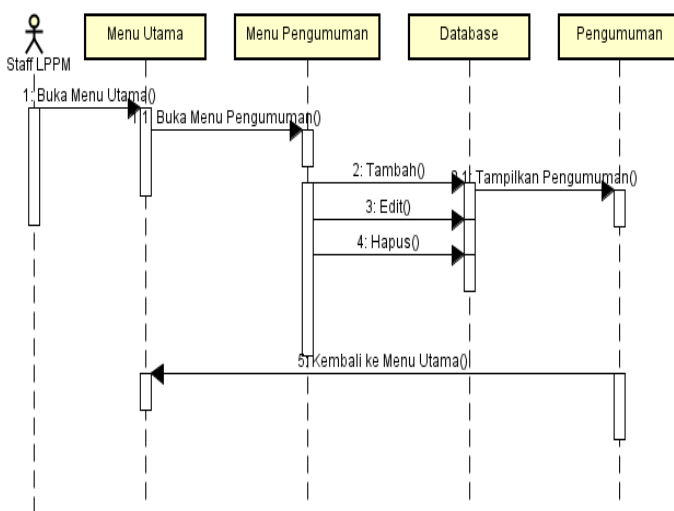

Gambar. 9 Sequence Diagram Pengumuman

\section{Sequence Diagram Kegiatan PPM}

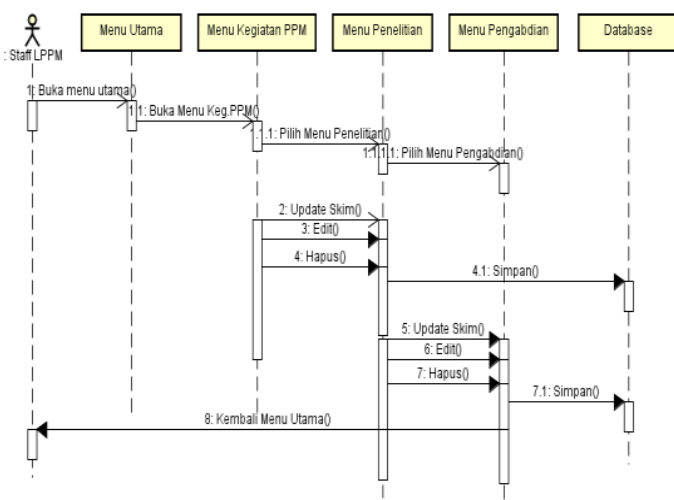

Gambar. 10 Sequence Diagram Kegiatan PPM

\section{Sequence Diagram Seminar} Proposal

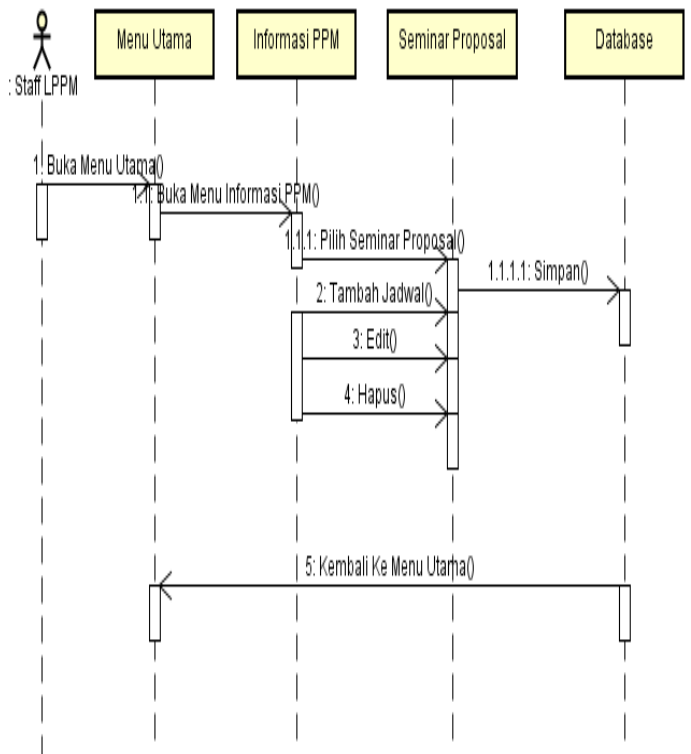

Gambar. 11 Sequence diagram Seminar Proposal 
5. Sequence Diagram Monitoring Evaluasi (Monev)

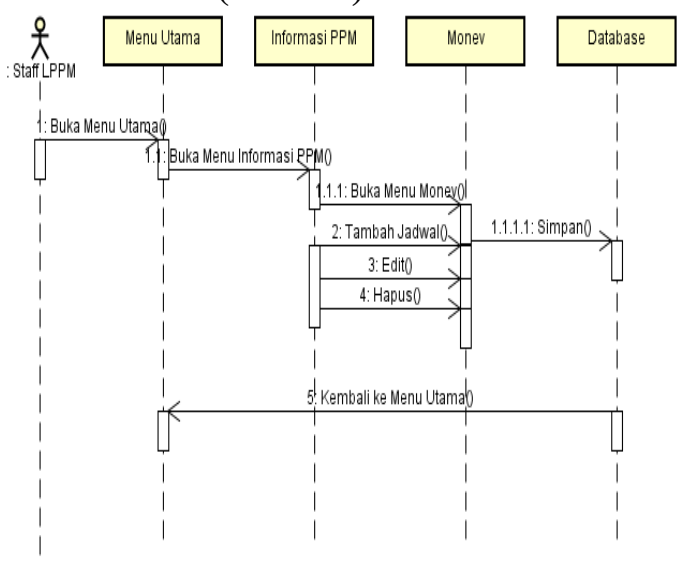

Gambar. 12 Sequence diagram Monitoring Evaluasi(Monev)

\section{Sequence Diagram Seminar Hasil}

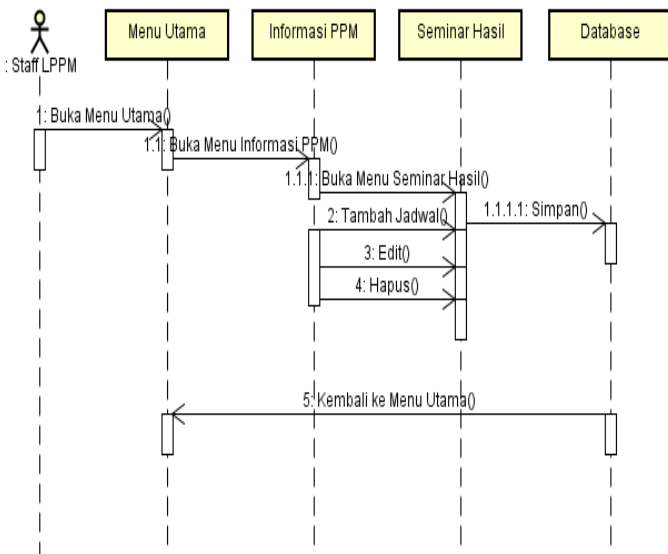

Gambar. 13 Sequence diagram Seminar Hasil

\section{Sequence diagram Login Staff} LPPM

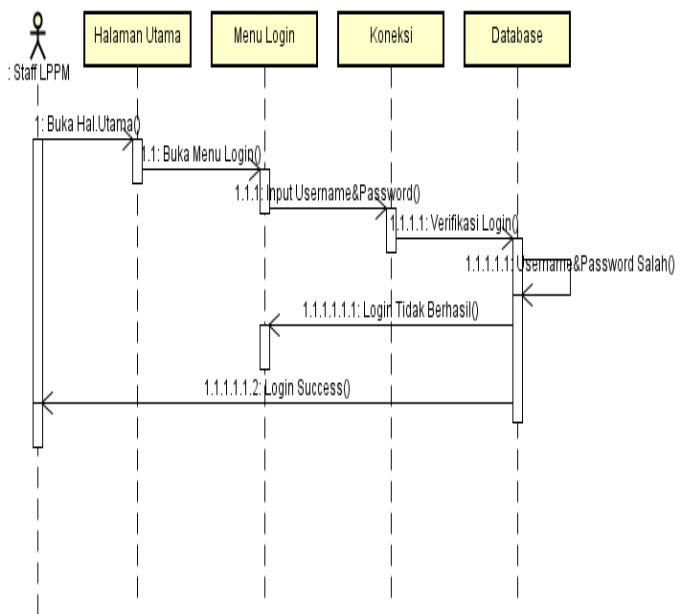

Gambar. 14 Sequence diagram Login Pada Staff LPPM

\section{Sequence Diagram Dosen Peneliti}

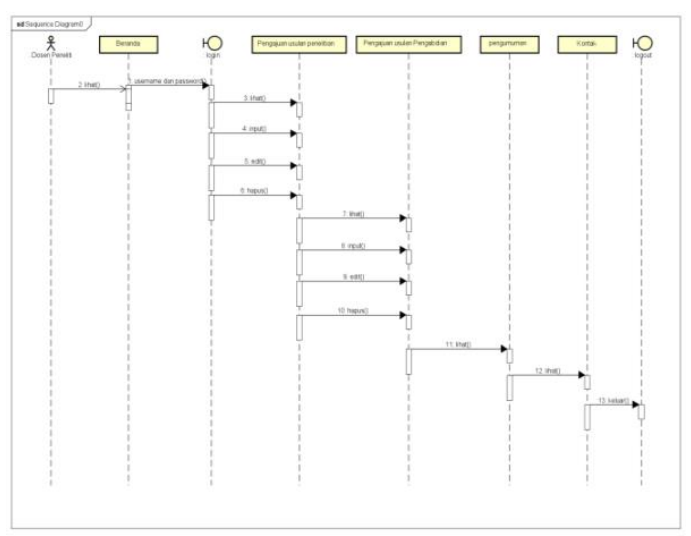

Gambar. 15 Sequence diagram Dosen Peneliti

9. Sequence Diagram Reviewer

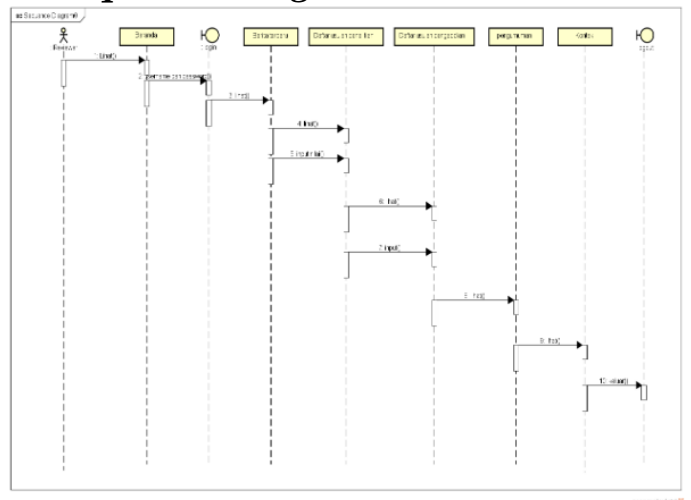

Gambar 16.Sequence Diagram Reviewer

Class Diagram

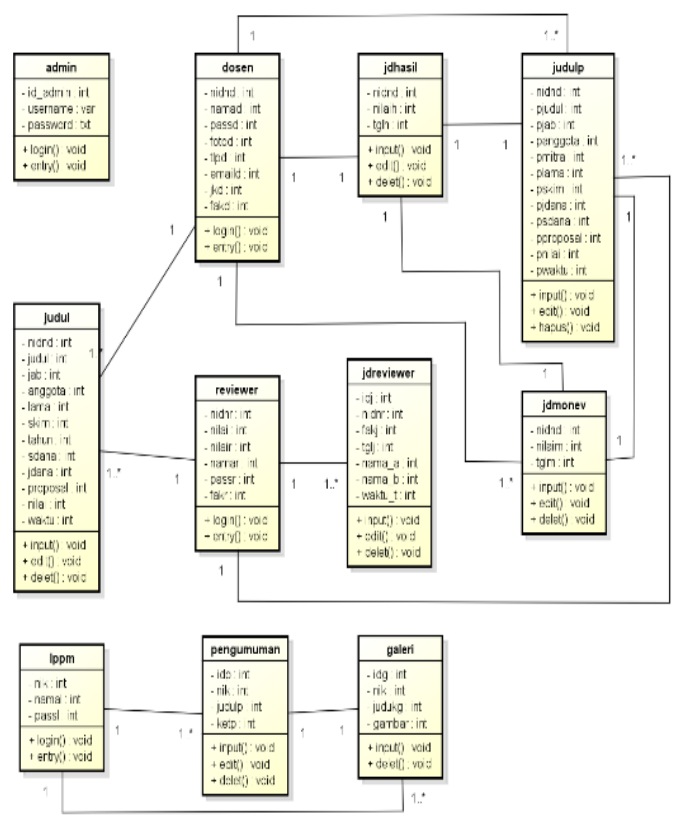

Gambar. 17 Class Diagram Sistem Informasi PPM 
Work System Framework memberikan gambaran sistem yang sedang dipelajari, mengidentifikasi masalah dan peluang, menggambarkan perubahan yang mungkin terjadi dan melacak bagaimana perubahan tersebut mungkin mempengaruhi bagian lain dari sistem kerja. Work System Framework dimana merinci tentang siapa pemakai sistem (customer), produk dan layanan system(product dan service), proses bisnis yang dilakukan (business process), pihak terlibat (participant), informasi (information), teknologi (Alter S., 2013).

1. Komponen-komponen pada Work

System Framework

Komponen-komponen yang ada pada Work System Framework adalah sebagai berikut (Rohman, 2009):

a. Customer

Customer adalah orang/ organisasi yang menerima secara langsung produk atau service yang dihasilkan oleh sistem, baik konsumen dari luar organisasi atau dan dalam organisasi. Customer terbagi menjadi pelanggan eksternal (masyarakat) yang menerima barang dan jasa serta pelanggan internal (dari dalam organisasi sendiri).

b. Product and Services

Product and Services merupakan gabungan dari benda berwujud fisik, informasi dan layanan yang dihasilkan oleh work system untuk para pelanggan. Tujuan terciptanya work system guna menghasilkan barang dan jasa.

c. Business Process

Business Process merupakan kumpulan urutan-urutan kerja atau aktivitas yang dijalankan di dalam work system.

\section{d. Participants}

Peserta (participants) adalah orang yang melakukan beberapa pekerjaan pada proses bisnis disebut sebagai peserta bagi work system.

e. Information

Informasi (Information) adalah yang digunakan oleh participants untuk mengerjakan pekerjaannya..

f. Technology

Teknologi (Technology) terdiri dari perangkat keras, perangkat lunak, dan perkakas-perkakas lainnya yang digunakan oleh peserta ketika melakukan pekerjaannya.

g. Context atau Environtment Merupakan bagian-bagian seperti organisasi, persaingan, teknis, dan peraturan yang terdapat pada work system yang sedang beroperasi.

h. Infrastructure

Infrastruktur (infrastructure) meliputi segala sumber daya, baik manusia, informasi, dan teknis yang digunakan oleh work system walaupun sumber-sumber daya ada dan dikelola di luar work system dan juga digunakan oleh work system lainnya.

i. Strategy

Hubungan antara komponen ini dengan strategi organisasi boleh saja tidak menjadi perhatian, namun terkadang dengan melihat strategi organisasi akan membantu dalam menjelaskan mengapa work system sepeti saat ini.

Semua komponen yang dijelaskan di atas merupakan representasi dari framework yang dapat digunakan untuk menyimpulkan atau meringkas work system apapun. Agar diperoleh sebuah analisis utuh mengenai keseluruhan work system dari perusahaan atau organisasi, maka 
masing-masing komponen harus diperhatikan keterkaitan dan hubungannya dengan komponen lain. Hal tersebut digambarkan melalui tanda panah bolak-balik dari satu komponen ke komponen lainnya. Penjelasan tersebut menggambarkan bahwa harus ada keseimbangan antara satu komponen dengan komponen lainnya (Alter S., 2013).

\section{Unified ModelingLanguage (UML)}

UML berfungsi sebagai jembatan dalam mengkomunikasikan beberapa aspek dalam sistem melalui sejumlah elemen grafis yang bisa diakomodasikan menjadi diagram. UML mempunyai banyak diagram yang dapat mengakomodasikan berbagai sudut pandang dari perangkat lunak yang terdiri dijelaskan pada sub-sub bab berikut ini.

\section{Use case Diagram}

Use case mendeskripsikan sebuah interaksi antara satu atau lebih actor dengan system informasi yang akan dibuat. Use case digunakan untuk mengetahui fungsi apa saja yang ada di dalam sebuah sistem informasi dan siapa saja yang berhak menggunakan fungsi-fungsi itu (Rosa, 2013). Usecase diagram memiliki tujuan untuk memvisualisasikan persyaratan fungsional dari suatu sistem, termasuk hubungan aktor yang akan berinteraksi dengan sistem, proses penting, serta hubungan antara kasus penggunaan yang berbeda (Lee, 2012).

2. Activity Diagram
Activity
diagram ini
menggambarkan workflow (aliran kerja) atau aktivitas dari sebuah sistem atau proses bisnis yang perlu diperhatikan adalah bahwa activity diagram menggambarkan aktivitas sistem bukan apa yang dilakukan

aktor, jadi aktivitas yang dapat dilakukan oleh sistem (Rosa, 2013). Activity diagram juga menggambarkan aliran prosedural kontrol antara dua atau lebih objek kelas saat memproses suatu kegiatan dapat ditampilkan dengan diagram aktivitas (Lee, 2012).

\section{Sequence Diagram}

Sequence diagram menjelaskan interaksi objek yang disusun berdasarkan urutan waktu. Secara mudahnya Sequence diagram adalah gambaran tahap demi tahap, termasuk kronologi (urutan) perubahan secara logis yang seharusnya dilakukan untuk menghasilkan sesuatu sesuai dengan Use case diagram.

\section{Class Diagram}

Class diagram menunjukkan bagaimana entitas yang berbeda (orang, benda, dan data ) berhubungan satu sama lain (Lee, 2012).

\section{SIMPULAN}

Berdasarkan penelitian dan pembahasan yang telah dilaksanakan, maka dapat disimpulkan beberapa hal sebagai berikut :

1. Dari hasil analisis sistem administrasi LPPM menggunakan metode Work System Framework diketahui kelemahan dari kondisi sistem lama karena masih banyak terjadi kesalahan dalam informasi yang berkaitan dengan informasi tawaran penelitian dan pengabdian masyarakat, jumlah penelitian yang telah dilakukan. Hal ini muncul karena pencatatan data masih bersifat manual dan tersimpan pada banyak file yang berakibat integritas dan validitas data tidak terjamin dengan baik. 
2. Penelitian yang dilakukan telah menghasilkan prototypesistem informasi administrasi kegiatan penelitian dan pengabdian masyarakat pada LPPM Universitas Lancang Kuning Pekanbaru yang dapat memberikan kemudahan bagi pihak terkait untuk melaksanakan kegiatan penelitian dan pengabdian masyarakat.

3. Pengujian prototype sistem informasi administrasi kegiatan penelitian dan pengabdian masyarakat yang telah dilaksanakan di LPPM Universitas Lancang Kuning Pekanbaru telah memberikan gambaran kepada LPPM Universitas Lancang Kuning Pekanbaru untuk dapat menggunakan sistem informasi dalam kegiatan administrasinya.

\section{DAFTAR PUSTAKA}

Alter, S. (2013). Work System Theory: Overview of Core Concepts, Extensions, and Challenges for the Future. Journal of the Association for Information Systems, 72

Dikti. (2016). Panduan Pelaksanaan Penelitian dan Pengabdian Masyarakat di Perguruan Tinggi. Direktorat Jenderal Penguatan Riset dan Pengembangan Kementerian Riset, Teknologi, dan Pendidikan Tinggi. Edisi X.

Hamzah, H. (2016). Sistem Informasi Kegiatan Penelitian dan Pengabdian Kepada Masyarakat Universitas Respati. Jurnal Teknologi dan Sistem Informasi (Teknosi), 2(2), 17-26

Lee, S. (2012). Unified Modeling Language (UML) for Database Systems and Computer Applications
Rohman, N. (2009). Sistem Pengolahan Data Kp dan Ta pada Program Studi If, Mi dan Ka Stmik Mardira Indonesia Bandung. Jurnal Computech \& Bisnis, 3(1), 1-13

Rosa, A. S., \& Shalahuddin, M. (2013). Rekayasa Perangkat Lunak Terstruktur dan Berorientasi Objek. Bandung: Informatika

Williandy, I., \& Fitriawan, H. (2016). Rancang Bangun Sistem Informasi Penelitian dan Pengabdian Kepada Masyarakat Fakultas Teknik Universitas Lampung Menggunakan PHP dan MySQL. Jurnal Rekayasa dan Teknologi Elektro (Electrician), 10(3), 192-200 